\title{
NILAI MANFAAT HUTAN MANGROVE DAN FAKTOR-FAKTOR PENYEBAB KONVERSI ZONA SABUK HIJAU (GREENBELT) MENJADI TAMBAK DI WILAYAH PESISIR KOTA SINGKAWANG KALIMANTAN BARAT
}

\author{
Slamet Jumaedi \\ Program Studi Teknologi Penangkapan Ikan. Jurusan Ilmu Kelautan dan Perikanan. Politeknik Negeri Pontianak \\ E-mail: Jumaedi_slmt@yahoo.co.id
}

\begin{abstract}
ABSTRAK. Penelitian ini bertujuan untuk Mengkaji kondisi dan potensi ekosistem mangrove di Pesisir Kota Singkawang, Menganalisis apa akar penyebab terjadinya alih fungsi Zona Sabuk Hijau (Greenbelt) Hutan mangrove menjadi tambak di Pesisir Kota Singkawang. Menentukan alternatif pengelolaan kawasan mangrove yang berkelanjutan di Pesisir Kota Singkawang, Kalimantan Barat. Faktor penyebab utama konversi Zona Sabuk Hijau (Greenbelt) ekosistem mangrove menjadi tambak diwilayah pesisir Kota Singkawang adalah (1) Tingginya kebutuhan ekonomi dan kurangnya kesadaran kepentingan ekologis serta kepedulian masyarakat akan dampak lingkungan, (2) Kurangnya pemahaman masyarakat tentang pentingnya penetapan Zona Sabuk Hijau (Green Belt) mangrove untuk kelestarian lingkungan. Hal ini yang mengakibatkan terjadinya perusakan hutan mangrove oleh masyarakat pesisir Kota Singkawang yang tentunya akan berdampak pada masa yang akan datang. Kemudian rendahnya kesadaran masyarakat tentang konversi dan fungsi ekosistem mangrove. (3) Berdasarkan Parameter fisik lingkungan mangrove Zona Sabuk Hijau (Green Belt) yang di amati terdiri dari Suhu Air, Kekeruhan/Turbiditas, Kecerahan Perairan Laut, dan Gelombang, untuk variabel kimiawi lingkungan mangrove yang diamati adalah Salinitas, Derajat Keasaman (pH air), Oksigen Terlarut (DO), dan Kandungan Unsur Hara (Nutrient) di wilayah pesisir Kota Singkawang yang mana kondisi fisik kimiawi ekosistem mangrove sangat baik dan sangat dimungkinkan untuk budidaya tambak udang.
\end{abstract}

Kata kunci: Ekosistem mangrove, Sabuk Hijau (Green Belt), Degradasi, strategi pengelolaan

\section{VALUE AND BENEFITS OF FOREST MANGROVE CONVERSION FACTORS CAUSE BELT GREEN ZONE (GREEN BELT) INTO POND IN THE COASTAL TOWN WEST KALIMANTAN SINGKAWANG}

\begin{abstract}
This study aimed to Assess the condition and potential of mangrove ecosystems in the Coastal Singkawang, Analyze what the root cause of the conversion of the Green Belt Zone (Greenbelt) mangrove forests into shrimp ponds on the Coastal Singkawang. Determining alternative sustainable management of mangrove areas in the Coastal Singkawang, West Kalimantan. The main factors conversions Zone Green Belt (Greenbelt) of mangrove ecosystems into pond region of the coastal city of Singkawang is (1) The high demand of the economy and lack of awareness of ecological importance and public concern about the environmental impact, (2) lack of public understanding of the importance of the establishment of Zone Green Belt (Green Belt) mangrove to environmental sustainability. This is resulting in the destruction of mangrove forests by coastal communities Singkawang will certainly have an impact on the future. Then the lack of public awareness about the conversion and the function of the mangrove ecosystem. (3) Based on Physical parameters mangrove environment Zone Green Belt (Green Belt) were observed consisting of Water Temperature, Turbidity / Turbidity Brightness Sea waters, and wave, to the variable chemical mangrove environment is observed salinity, degree of acidity ( $\mathrm{pH}$ of water), Dissolved Oxygen (DO), and the content of Nutrients (Nutrient) in coastal areas Singkawang where the physical condition of the mangrove ecosystem is very good chemistry and it is possible to shrimp aquaculture.
\end{abstract}

Key words: mangrove ecosystems, Green Belt, degradation, management strategies

\section{PENDAHULUAN}

Kota Singkawang secara geografis terletak pada $0^{\circ} 44^{\prime} 57,57^{\prime \prime}-01^{\circ} 00^{\prime} 48,65^{\prime \prime}$ Lintang Utara (LU) dan $108^{\circ} 52^{\prime} 14,19^{\prime \prime}-109^{\circ} 09^{\prime} 46,22^{\prime \prime}$ Bujur Timur (BT), dengan luas $504 \mathrm{Km}^{2}$ (50.400 ha). Kota Singkawang merupakan salah satu Kota di Kalimantan Barat yang terbentuk pada tanggal 17 Oktober 2001 berdasarkan Undang-Undang (UU) No. 12 tahun 2001. Kota ini merupakan pemekaran dari wilayah Kabupaten Bengkayang, Secara geografis Kota Singkawang sebelah barat berbatasan dengan Laut Natuna, sebelah timur dan selatan berbatasan dengan Gunung Raya Pasi, Poteng, dan Roban. Sebagian besar wilayah Kota Singkawang merupakan pesisir dan perairan laut sehingga potensi pembangunan banyak berada pada kawasan ini.

Kawasan mangrove memiliki peranan yang sangat penting, maka diperlukan pengelolaan yang pada dasarnya memberikan legitimasi agar dapat tetap lestari. Upaya memberikan legitimasi kawasan hutan mangrove sebagai suatu bentuk sabuk hijau (Greenbelt) di sepanjang pantai dan tepi sungai sebagai areal yang dilindungi dikuatkan dengan Surat Keputusan Bersama Menteri Pertanian dan Menteri Kehutanan No. KB 550/264/Kpts/4/1984 dan No. 082/Kpts-II/1984 tanggal 30 April 1984 yang di antaranya menyebutkan bahwa lebar sabuk hijau hutan mangrove adalah $200 \mathrm{~m}$. Surat Keputusan Bersama ini selanjutnya dijabarkan oleh 
Departemen Kehutanan dengan mengeluarkan Surat Edaran No. 507/IV-BPHH/1990 yang di antaranya berisi penentuan lebar sabuk hijau pada hutan mangrove, yaitu selebar $200 \mathrm{~m}$ di sepanjang pantai dan $50 \mathrm{~m}$ di sepanjang tepi sungai.

Penentuan lebar sabuk hijau tersebut selanjutnya lebih dikuatkan lagi dengan Keputusan Presiden No.32 tahun 1990 tentang Pengelolaan Kawasan Lindung. Dalam Keppres tersebut ditetapkan bahwa perlindungan terhadap sempadan pantai dilakukan untuk melindungi wilayah pantai dari kegiatan yang mengganggu kelestarian fungsi pantai, di mana kriteria sempadan pantai yang dimaksud adalah daratan sepanjang tepian yang lebarnya proporsional dengan bentuk dan kondisi pantai, minimum $100 \mathrm{~m}$ dari titik pasang tertinggi ke arah darat. Selanjutnya berdasarkan hasil kajian ekologis, disarankan lebar sabuk hijau pada kawasan pantai berhutan mangrove minimal selebar 130 dikalikan nilai rata-rata perbedaan antara air pasang tertinggi dan terendah tahunan yang diukur dari air surut terendah ke arah daratan.

Zona Sabuk hijau (Greenbelt) Hutan mangrove di Kota Singkawang sesuai Surat Keputusan Bersama Menteri Pertanian dan Menteri Kehutanan No. KB 550/264/Kpts/4/1984 dan No. 082/Kpts-II/1984 tanggal 30 April 1984 yang di antaranya menyebutkan bahwa lebar sabuk hijau hutan mangrove adalah 200 m., akan tetapi tidak sepenuhnya dapat melindungi ekosistem mangrove dari kerusakan dan degradasi. Zona Sabuk hijau (Greenbelt) Kawasan mangrove di Kota Singkawang ini mengalami kerusakan karena sebagian telah dikonversi menjadi tambak. Pengambilan pohon mangrove untuk kayu bakar dan arang oleh masyarakat setempat juga ikut menambah kerusakan hutan mangrove di Kota
Singkawang ini. Kegiatan ini akan berdampak negatif pada ekosistem pesisir dan lautan. Degradasi ekosistem mangrove di Kota Singkawang akibat berbagai aktifitas pemanfaatan seperti konversi untuk lahan tambak dan pengambilan kayu/penebangan liar perlu mendapat perhatian khusus dari semua pihak.

Melihat hal tersebut, maka menjadi sangat penting untuk diketahui (1) Kondisi dan potensi ekosistem mangrove di Pesisir Kota Singkawang, (2) Menganalisis apa akar penyebab terjadinya alih fungsi Zona Sabuk Hijau Hutan (Greenbelt) menjadi tambak di Pesisir Kota Singkawang. (3) Menentukan alternatif pengelolaan kawasan mangrove yang berkelanjutan di Pesisir Kota Singkawang, Kalimantan Barat.

Penelitian ini akan berusaha menjawab berbagai pertanyaan tersebut dan mencari akar penyebab permasalahan alih fungsi lahan mangrove Zona Sabuk Hijau (Greenbelt) menjadi tambak sehingga dapat dirumuskan alternatif pengelolaan yang tepat terkait dengan masalah tersebut.

\section{METODE}

Penelitian ini dilaksanakan di kawasan Zona Sabuk Hijau (Greenbelt) ekosistem mangrove Kota Singkawang, Kalimantan Barat selama 3 bulan, dari bulan Februari sampai April 2012. Pemilihan obyek penelitian dilakukan dengan sengaja (purposive sampling) dengan pertimbangan lokasi terdapat hutan mangrove dan tambak yang memerlukan pengelolaan dan pelestarian karena penurunan kuantitas (luasan). Lokasi penelitian dan titik sampling mangrove dapat dilihat pada Gambar 1.

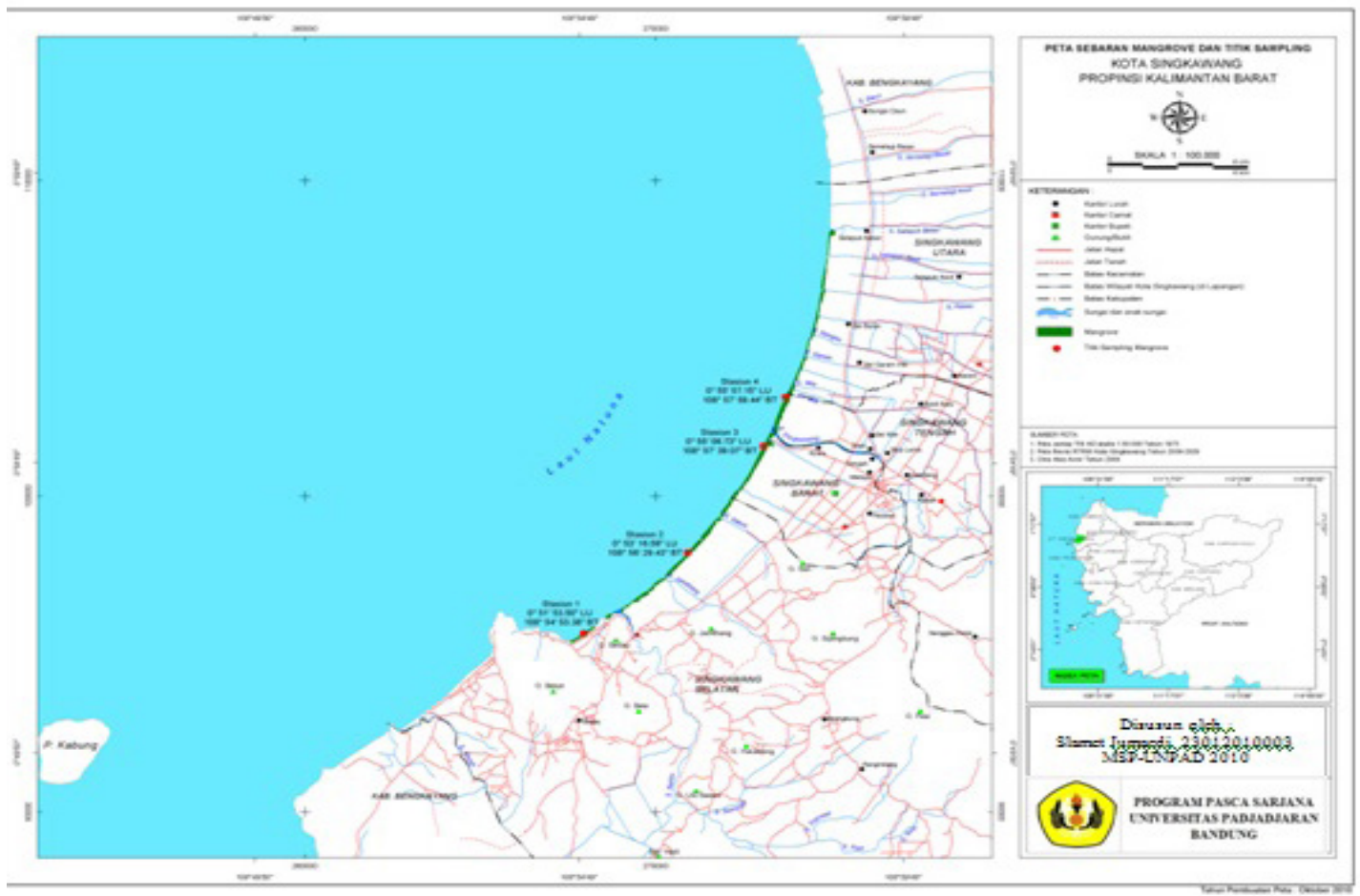

Gambar 1. Peta lokasi penelitian dan titik sampling mangrove 


\section{Pengumpulan Data}

Metode yang digunakan dalam penelitian ini adalah metode survey, Focus Group Discussion (FGD) dan teknik wawancara secara mendalam (depth interview). Metode survey digunakan untuk pengambilan data mengenai ekosistem mangrove, data fisik dan kimiawi perairan. Metode Focus Group Discussion (FGD) dan wawancara digunakan untuk pengambilan data tentang sosial, budaya, ekonomi masyarakat dan pandangan masyarakat terhadap pengelolaan ekosistem mangrove.

Penarikan sampel untuk data vegetasi dan aspek fisika kimia lingkungan mangrove terbagi atas 6 jalur transek (garis berpetak) tegak lurus garis pantai ke arah darat. Pengambilan data vegetasi untuk tingkat semai (diameter $<2 \mathrm{~cm}$ ) dilakukan pada petak $2 \times 2 \mathrm{~m}^{2}$, pancang (diameter $2-10 \mathrm{~cm}$ ) pada petak $5 \times 5 \mathrm{~m}^{2}$, dan pohon (diameter $\geq 10 \mathrm{~cm}$ ) pada petak $10 \times 10 \mathrm{~m}^{2}$. Data nilai manfaat ekonomi ekosistem mangrove dan tambak didapatkan melalui kuisioner yang diberikan kepada responden.

Data yang diambil dalam penelitian ini adalah data primer dan data sekunder. Data primer diperoleh secara langsung di lokasi penelitian dengan teknik survei dengan menggunakan kuisioner kepada responden dan wawancara mendalam, serta wawancara tidak terstruktur dengan masyarakat lokal, pengelola kawasan lindung lembaga swadaya masyarakat (LSM), dan instansi yang terkait. Data sosial ekonomi yang dibutuhkan dalam penelitian ini meliputi data penduduk dan riwayatnya, tingkat pendidikan, mata pencaharian dan pendapatan penduduk, tingkat pemanfaatan mangrove oleh masyarakat, sarana prasarana, serta pandangan masyarakat terhadap pengelolaan mangrove Selain itu juga dikumpulkan berbagai data penunjang seperti kondisi fisik wilayah, sejarah dan pola penguasaan lahan, program dan kebijakan pemerintah, serta peraturan perundangan.

\section{Analisis Data}

\section{Analisis struktur vegetasi mangrove}

Analisis terhadap struktur vegetasi mangrove mengacu pada English et al. (1997) yaitu dengan menghitung kerapatan spesies $\left(\mathrm{D}_{\mathrm{i}}\right)$, kerapatan relatif spesies $\left(\mathrm{RD}_{\mathrm{i}}\right)$, frekuensi spesies $\left(\mathrm{F}_{\mathrm{i}}\right)$, frekuensi relatif spesies $\left(\mathrm{RF}_{\mathrm{i}}\right)$, penutupan spesies $\left(\mathrm{C}_{\mathrm{i}}\right)$, dan penutupan relatif spesies $\left(\mathrm{RC}_{\mathrm{i}}\right)$ untuk mendapatkan indek nilai penting species $\left(\mathrm{INP}_{\mathrm{i}}\right.$ ). $\mathrm{INP}_{\mathrm{i}}$ berkisar antara 0 sampai 300 dan memberikan suatu gambaran mengenai pengaruh atau peranan suatu jenis tumbuhan mangrove dalam komunitas mangrove.

\section{Analisis nilai manfaat ekonomi ekosistem mangrove dan tambak}

Mengacu pada Adrianto (2006), nilai ekonomi total manfaat hutan mangrove pada penelitian ini terdiri dari nilai manfaat langsung (hasil hutan dan perikanan), nilai manfaat tidak langsung (penahan abrasi, interusi air laut dan penyedia unsur hara), nilai manfaat pilihan dan nilai keberadaan. Nilai manfaat ekonomi tambak (NMET) dihitung berdasarkan hasil panen udang dikurangi dengan biaya tetap dan biaya operasional.

Perhitungan nilai manfaat ekonomi ekosistem mang-rove dan tambak ditujukan untuk mengetahui nilai suatu sumberdaya alam (mangrove) jika dibandingkan dengan nilai pemanfaatan lain (tambak), sehingga dapat diketahui mana yang lebih menguntungkan.

Analisis faktor penyebab konversi Zona Sabuk Hijau (Greenbelt) dan persepsi masyarakat terhadap pengelolaan ekosistem mangrove

Pandangan masyarakat terhadap pengelolaan eko-sistem mangrove dihitung dari hasil kuisioner (50 responden) dengan menggunakan rating scale. Kategori tingkat nilai $(\mathrm{N})$ terdiri dari sangat baik $(\mathrm{N}>75 \%)$, baik $(50<\mathrm{N} \leq 75 \%)$, buruk $(25<\mathrm{N} \leq 50 \%)$ dan sangat buruk $(\mathrm{N} \leq 25 \%)$.

\section{HASIL DAN PEMBAHASAN}

\section{Luas Ekosistem Mangrove dan Tambak}

Luas hutan mangrove di Pesisir Kota Singkawang Berdasarkan Data Dinas Kelautan dan Perikanan Kota Singkawang per 1 Januari 2012 luasan hutan mangrove di Pesisir Kota Singkawang yaitu seluas 101,51 ha. Luas tambak pada dipesisir Kota Singkawang tahun 2012 adalah 80 ha

\section{Struktur Vegetasi Mangrove}

Berdasarkan hasil observasi/pengamatan di lapangan, tidak kurang dari 7 (tujuh) jenis vegetasi mangrove ditemukan hidup di pesisir Singkawang. Jenis vegetasi mangrove yang hidup di pesisir Singkawang tersebut meliputi Avicennia alba, Avicennia lanata, Sonneratia alba, Rhizophora apiculata, Rhizophora mucronata, Bruguiera cylindrica, dan Excoecaria agallocha. Akan tetapi berdasarkan hasil sampling, hanya ditemukan 4 (empat) jenis tumbuhan mangrove yang berada dalam petak pengamatan. Jenis vegetasi mangrove tersebut antara lain Avicennia alba, Sonneratia alba, Rhizophora mucronata dan Excoecaria agallocha. Komunitas perintis (dekat laut) umumnya terdiri dari Sonneratia alba dan Avicennia alba. Di belakang kedua asosiasi tersebut di ikuti Rhizophora apiculata. Kearah daratan lebih jauh ditemukan beberapa Bruguiera gymnorhiza, sedikit Xylocarpus granatum dan Xylocarpus moluccensis yang berasosiasi dengan Rhizophora apiculata. Xylocarpus granatum, Xylocarpus moluccensis dan Excoecaria agallocha dapat ditemui di pinggiran/pematang sungai. Asosiasi Nipah tumbuh subur di pinggir-pinggir sungai kearah hulu sampai batas pasang surut maksimal.

Hal ini sesuai dengan pendapat Bengen (2004), bahwa daerah yang paling dekat dengan laut, yang 
biasanya bersubstrat agak berpasir, sering ditumbuhi oleh jenis Avicennia spp. Bisa pula berasosiasi dengan Sonneratia spp., yang dominan tumbuh pada lumpur dalam. Sementara makin ke arah darat, hutan mangrove didominasi oleh jenis Rhizopora spp., juga Bruguiera spp. dan Xylocarpus. Sementara zonasi berikutnya banyak diisi oleh Bruguiera spp. Zona transisi antara hutan mangrove dan dataran rendah biasa ditumbuhi oleh nipah (Nypa fruticans) dan beberapa spesies palem lainnya.

\section{Kerapatan, frekuensi, penutupan dan Indeks Nilai Penting (INP) jenis mangrove}

Kerapatan, frekuensi, penutupan dan Indeks Nilai Penting (INP) jenis mangrove tertinggi terdapat pada jenis Avicennia alba baik untuk tingkat pohon, pancang maupun semai kemudian di ikuti oleh jenis Sonneratia alba, Rhizophora mucronata, dan Excoecaria agallocha. Untuk lebih lengkapnya dapat dilihat pada Tabel 1.

Secara umum, kerapatan vegetasi mangrove di PesisirSingkawang adalah $327 \mathrm{btg} /$ hauntuk pohon, 11.275 btg/ha untuk pancang dan 50.625 btg/ha untuk semai. Jika kerapatan vegetasi mangrove di Pesisir Singkawang dibandingkan dengan Kriteria Baku Kerusakan Mangrove (Tabel 3.1), maka untuk tingkatan pohon dapat dikategorikan jarang/rusak yaitu kerapatan dibawah 1000 btng/ha. Untuk tingkatan pancang kerapatan mangrove di pesisir Singkawang dapat dikategorikan sangat padat (baik) dengan kerapatan di atas 1500 btng/ha.

Indeks nilai penting tertinggi (INP) jenis mangrove pada tingkat pohon, pancang dan semai terdapat pada jenis Avicennia alba yang secara berturutturut nilainya $265,95 \%$; 259,80\%; dan $200 \%$. Selanjutnya di ikuti oleh Sonneratia alba dengan nilai INP untuk tingkat pohon dan pancang secara berturutturut sebesar $25,10 \%$ dan $27,07 \%$.

INP terendah jenis mangrove pada tingkat pohon terdapat pada Rhizophora mucronata dengan nilai 8,96 $\%$. INP terendah untuk tingkat pancang terdapat pada jenis Excoecaria agallocha dan Rhizophora mucronata yang secara berturut-turut nilainya $4,05 \%$ dan $9,09 \%$.

\section{Nilai Manfaat Ekonomi Ekosistem Hutan Mangrove}

a. Nilai manfaat langsung (Direct Use Value)

Nilai manfaat langsung ekosistem mangrove di pesisir Kota Singkawang terdiri dari nilai manfaat hasil hutan dan nilai manfaat hasil perikanan.

Tabel 1. Rekapitulasi Struktur Vegetasi Hutan Mangrove di Pesisir Kota Singkawang

\begin{tabular}{|c|c|c|c|c|c|c|c|c|c|}
\hline $\mathbf{N}$ & Jenis & Nama lokal & Di (Btg/ha) & RDi (\%) & $\mathbf{F i}$ & RFi (\%) & $\mathbf{C i}$ & RCi (\%) & INP (\%) \\
\hline \multicolumn{10}{|c|}{ Tingkat Pohon } \\
\hline 1 & Avicennia alba & Api-api & 297,92 & 92,92 & 1,00 & 80,00 & 3,40 & 93,02 & 265,95 \\
\hline 2 & Sonneratia alba & Perepat & 20,83 & 5,15 & 0,21 & 15,00 & 0,23 & 4,94 & 25,10 \\
\hline 3 & Rhizophora mucronata & Bakau & 8,33 & 1,92 & 0,08 & 5,00 & 0,10 & 2,03 & 8,96 \\
\hline \multirow[t]{2}{*}{4} & Excoecaria agallocha & Buta-buta & 0,00 & 0,00 & 0,00 & 0,00 & 0,00 & 0,00 & 0,00 \\
\hline & TOTAL & & 327,08 & 100,00 & 1,29 & 100,00 & 3,73 & 100,00 & 300,00 \\
\hline \multicolumn{10}{|c|}{ Tingkat Pancang } \\
\hline 1 & Avicennia alba & Api-api & 10950,00 & 97,22 & 7,00 & 66,07 & 34,61 & 96,50 & 259,80 \\
\hline 2 & Sonneratia alba & Perepat & 241,67 & 2,07 & 0,42 & 22,62 & 0,83 & 2,38 & 27,07 \\
\hline 3 & Rhizophora mисronata & Bakau & 58,33 & 0,50 & 0,15 & 7,74 & 0,29 & 0,85 & 9,09 \\
\hline \multirow[t]{2}{*}{4} & Excoecaria agallocha & Buta-buta & 25,00 & 0,21 & 0,06 & 3,57 & 0,10 & 0,27 & 4,05 \\
\hline & TOTAL & & 11275,00 & 100,00 & 7,63 & 100,00 & 35,83 & 100,00 & 300,00 \\
\hline \multicolumn{10}{|c|}{ Tingkat Semai } \\
\hline 1 & Avicennia alba & Api-api & 50625,00 & 100,00 & 1,00 & 100,00 & - & - & 200,00 \\
\hline 2 & Sonneratia alba & Perepat & 0,00 & 0,00 & 0,00 & 0,00 & - & - & 0,00 \\
\hline 3 & Rhizophora mucronata & Bakau & 0,00 & 0,00 & 0,00 & 0,00 & - & - & 0,00 \\
\hline \multirow[t]{2}{*}{4} & Excoecaria agallocha & Buta-buta & 0,00 & 0,00 & 0,00 & 0,00 & - & - & 0,00 \\
\hline & TOTAL & & 50625,00 & 100,00 & 1,00 & 100,00 & - & - & 200,00 \\
\hline
\end{tabular}


Nilai Manfaat Hasil Hutan, Nilai manfaat langsung hasil hutan ekosistem mangrove di pesisir Kota Singkawang dapat di estimasi dari besarnya nilai potensi kayu yang besarnya tergantung dari volume kayu. Berdasarkan hasil sampling, rata-rata volume kayu mangrove di pesisir Kota Singkawang adalah sebesar $149,02 \mathrm{~m}^{3} / \mathrm{ha}$. Nilai manfaat potensi kayu mangrove di pesisir Kota Singkawang dapat dilihat pada Tabel 2.

Tabel 2. Nilai manfaat potensi kayu komersial

\begin{tabular}{|c|c|c|c|}
\hline No & Uraian & Satuan & Jumlah \\
\hline 1 & Luas hutan mangrove & $\mathrm{Ha}$ & 101,51 \\
\hline 2 & Potensi kayu & $\mathrm{m}^{3} / \mathrm{ha}$ & 149,02 \\
\hline 3 & Harga jual & $\mathrm{Rp} / \mathrm{m}^{3}$ & $200.000,00$ \\
\hline 4 & Nilai total & $\mathrm{Rp}$ & $3.0254 .04040,00$ \\
\hline 5 & Nilai (daur 20 tahun) & $\mathrm{Rp} / \mathrm{thn}$ & $151.270 .202,00$ \\
\hline 6 & Biaya (35\% dari Nilai) & $\mathrm{Rp} / \mathrm{thn}$ & $52.944 .570,70$ \\
\hline 7 & Pendapatan & $\mathrm{Rp} / \mathrm{thn}$ & $98.325 .631,30$ \\
\hline 8 & Pendapatan per hektar & $\mathrm{Rp} / \mathrm{thn}$ & $659.815,00$ \\
\hline
\end{tabular}

Nilai Manfaat Hasil Perikanan, Nilai manfaat langsung hasil perikanan ekosistem mangrove di pesisir Kota Singkawang dapat di estimasi dari besarnya produksi produk perikanan yang berasosiasi dengan ekosistem mangrove. Berdasarkan Statistik Dinas Kelautan dan Perikanan Kota Singkawang Tahun 2008, produksi hasil tangkapan ikan yang berasosiasi dengan dengan ekosistem mangrove di pesisir Kota Singkawang adalah sebesar 456,2 ton/tahun atau senilai dengan Rp. 7.837.560.000,-/tahun. Hasil tangkapan ikan tersebut (dianggap berasosiasi dengan ekosistem mangrove) berupa ikan manyung (Netuma thalassina), kurisi (Nemimterus hexodon), gulamah (Nibea albiflora), pari (Dasyatis spp), kembung (Rastrellinger brachysoma), bawal (Pampus argenteus), selar (Selaroides spp), kuwe (Caranx spp), golok-golok (Chirocentrus dorab), udang putih (Panaeus merguiensis), udang dogol(Metapenaeus ensis)dan udang lainnya. Jika luas hutan mangrove di Singkawang adalah 101,51 ha, maka nilai manfaat langsung hasil perikanan ekosistem mangrove di pesisir Kota Singkawang adalah Rp.77.209.733,03/ha/thn (Rp. 7.837.560.000,-/tahun : 101,51 ha).

b. Nilai manfaat tidak langsung (Indirect Use Value) Manfaat tidak langsung ekosistem mangrove dapat dilihat pada Tabel 3 .

c. Nilai Manfaat Pilihan

Berdasarkan Ruitenbeek (1991) nilai keanekaragaman hayati mangrove di Indonesia adalah US \$ 15 / ha/thn, maka nilai manfaat pilihan hutan mangrove di Pesisir Kota Singkawang adalah sebesar Rp.
151.200,- /ha/tahun. Luas hutan mangrove di pesisir Kota Singkawang adalah sebesar 101,51 ha, sehingga nilai manfaat pilihan yang dapat diperoleh adalah sebesar Rp.15.348.313,-/tahun adalah sebesar Rp.151 200.00 /ha/thn atau Rp.354 751488.00 /thn apabila nilai tukar dolar sebesar Rp.10 080.00-/US \$.

Tabel 3. Nilai manfaat tidak langsung ekosistem mangrove

\begin{tabular}{llrr}
\hline No & Jenis Manfaat & $\begin{array}{c}\text { Nilai Manfaat (Rp/ } \\
\text { thn) }\end{array}$ & $\begin{array}{c}\text { Persentase } \\
(\%)\end{array}$ \\
\hline $1 \quad \begin{array}{l}\text { Penahan abrasi } \\
\text { pantai }\end{array}$ & $3.768 .311 .400,00$ & 22,61 \\
2 & $\begin{array}{l}\text { Pencegah } \\
\text { intrusi air laut }\end{array}$ & $12.888 .225 .000,00$ & 77,32 \\
3 & $\begin{array}{l}\text { Penyedia unsur } \\
\text { hara }\end{array}$ & 12947712,16 & 0,08 \\
& Jumlah & $16.669 .484 .112,16$ & 100,00 \\
\hline
\end{tabular}

d. Nilai Manfaat Keberadaan

Nilai keberadaan ekosistem mangrove yang diberikan oleh masyarakat sekitar kawasan rata-rata sebesar Rp. 3.000.000,00/ha/thn atau Rp.12.500.000,00 /thn.

Berdasarkan perhitungan di atas maka nilai keberadaan ekosistem hutan mangrove yang diberikan oleh masyarakat sekitar kawasan rata-rata sebesar Rp. 5.640.000,- perhektar pertahun. Jika luas hutan mangrove di pesisir Kota Singkawang sebesar 101,51 ha, maka secara total nilai manfaat keberadaan ekosistem mangrove di pesisir Kota Singkawang adalah sebesar Rp.572.516.400,-/tahun. Untuk selengkapnya dapat dilihat pada Tabel 4.

Nilai total manfaat ekonomi ekosistem mangrove (Rp. 2.481.847.54,76/ha/thn) memiliki nilai yang jauh lebih tinggi jika dibandingkan dengan tambak yang hanya sebesar Rp. 16.623.454,00/ha/thn. Hal ini artinya lebih menguntungkan mangrove dibiarkan lestari dari pada di konversi menjadi tambak.

\section{Nilai Ekonomi Tambak di Kawasan Hutan Mangrove}

Berdasarkan hasil pengamatan di lapangan dan wawancara dengan petambak, nilai manfaat ekonomi tambak yang luasnya 80 ha adalah sebesar Rp.1.329.876.320,00/thn atau Rp. 16.623.454,00/ha/ thn.

Analisis Faktor Penyebab Konversi Zona Sabuk Hijau(Greenbelt) Ekosistem Mangrove Menjadi Tambak

Hal yang menyebabkan terjadinya konversi Zona Sabuk hijau (Greenbelt) lahan mangrove sebesar 80 hektar menjadi tambak di pesisir kota Singkawang adalah karena hutan mangrove yang mengalami penurunan produktivitas akibat pemanfaatan atau pengeksploitasian ekosistem mangrove secara besar-besaran oleh masya- 
Tabel 4. Total nilai manfaat ekosistem mangrove.

\begin{tabular}{clrrr}
\hline No & Jenis Manfaat & Nilai Manfaat (Rp/Thn) & Nilai Manfaat Rata-rata (Rp/ & \multicolumn{1}{c}{ Ha/Th) } \\
\hline 1 & Manfaat Langsung & $7.935 .885 .631,30$ & $781.783 .63,03$ & 31,50 \\
2 & Manfaat Tidak Langsung & $16.669 .484 .112,16$ & $164.215 .191,73$ & 66,17 \\
3 & Manfaat Pilihan & $15.348 .312,00$ & $1.51 .200,00$ & 0,06 \\
4 & Manfaat Keberadaan & $572.516 .400,00$ & $5.640 .000,00$ & 2,27 \\
\hline & Jumlah & $25.193 .234 .455,46$ & $2.481 .847 .54,76$ & 100,00 \\
\hline
\end{tabular}

rakat pesisir Kota Singkawang tanpa diikuti proses rehabilitasi kembali ekosistem mangrove tersebut. Dahulu masyarakat pesisir kota Singkawang Kalimantan Barat bisa dengan mudah mendapatkan komoditas yang dapat dimanfaatkan untuk memenuhi kehidupan sehari-sehari maupun untuk diperdagangkan dari hutan mangrove ini, tetapi seiring dengan berjalannya waktu, potensial produktivitas mangrove mengalami penurunan sehingga masyarakat pesisir Kota Singkawang memilih alternatif pengalihan fungsi lahan mangrove menjadi pertambakan, berikut ini adalah hal-hal yang menjadi faktor penyebab utama konversi ekosistem mangrove menjadi tambak diwilayah pesisir Kota Singkawang adalah sbb:

1. Berdasarkan pengamatan variabel Kehidupan sosial masyarakat lokal akibat alih fungsi ekosistem mangrove menjadi tambak di lingkungan mereka dengan mengkaji : (a) Struktur penduduk (b) Perilaku (c) Pranata sosial (d) Pola Penguasaan Lahan di Kawasan pesisir Kota Singkawang (e) Pandangan Masyarakat Terhadap Pengelolaan Ekosistem Mangrove hampir 90 persen kawasan hutan mangrove bagian utara di pesisir Kota Singkawang mengalami kerusakan karena perubahan tambak perikanan oleh masyarakat yang tidak memiliki prosedur dan izin dari pemerintah. Salah satu faktor terbesar ini terjadi adalah tingginya kebutuhan ekonomi dan kurangnya kesadaran kepentingan ekologis serta kepedulian masyarakat akan dampak lingkungan. Dan tanpa disadari telah merusak ekosistem kawasan mangrove pantai Utara Kota Singkawang.

2. Kurangnya pemahaman masyarakat tentang pentingnya penetapan Zona Sabuk Hijau (Green Belt) mangrove untuk kelestarian lingkungan. Hal ini yang mengakibatkan terjadinya perusakan hutan mangrove oleh masyarakat pesisir Kota Singkawang yang tentunya akan berdampak pada masa yang akan datang. Kemudian rendahnya kesadaran masyarakat tentang konversi dan fungsi ekosistem mangrove

3. Hutan rawa dalam lingkungan yang asin di daerah pesisir selalu dianggap daerah yang yang marginal atau sama sekali tidak cocok untuk pertanian dan akuakultur. Namun karena kebutuhan lahan pertanian dan perikanan yang semakin meningkat maka hutan mangrove dianggap sebagai lahan alternatif. Berdasarkan Parameter fisik lingkungan mangrove yang di amati terdiri dari suhuair dan gelombang, untuk variabel kimiawi lingkungan mangrove yang diamati adalah salinitas, Derajat Keasaman (pH air), Oksigen Terlarut (DO), Kekeruhan/Turbiditas, Kecerahan Perairan Laut, dan Kandungan Unsur Hara (Nutrient) di wilayah pesisir Kota Singkawang yang mana kondisi fisik kimiawi ekosistem mangrove sangat baik dan sangat dimungkinkan untuk budidaya tambak udang. Reklamasi seperti ini telah memusnakan ekosistem mangrove dan juga mengakibatkan efek-efek yang negatif terhadap perikanan di perairan pantai pesisir Kota Singkawang. Selain itu kehadiran saluransaluran drainase mengubah sistem hidrologi air tawar di daerah mangrove yang masih utuh yang terletak kearah laut menjadi tidak berfungsi dan hal ini mengakibatkan dampak negatif.

\section{Pandangan Masyarakat Terhadap Pengelolaan Eko- sistem Mangrove}

Pandangan terhadap pengelolaan Ekosistem Mangrove adalah sebesar $49.1 \%$, yang artinya masyarakat masih memandang pengelolaan Ekosistem Mangrove di Pesisir Kota Singkawang selama ini berjalan buruk.

\section{Sintesa dan Alternatif Solusi Kebijakan Pengelolaan}

Alternatif solusi kebijakan dalam pengelolaan ekosistem mangrove di Pesisir Kota Singkawang guna menghasilkan performance yang baik adalah dengan memperbaiki dan memperkuat struktur kelembagaan, antara lain dengan cara :

a. Batas (zonasi) Sabuk hijau (Greenbelt) sebagai areal yang dilindungi sesuai dengan Surat Keputusan Bersama Menteri Pertanian dan Menteri Kehutanan No. KB 550/264/Kpts/4/1984 dan No. 082/KptsII/1984 tanggal 30 April 1984 yang di antaranya menyebutkan bahwa lebar sabuk hijau hutan mangrove adalah $200 \mathrm{~m}$. Surat Keputusan Bersama ini selanjutnya dijabarkan oleh Departemen Kehutanan dengan mengeluarkan Surat Edaran No. 507/IVBPHH/1990 yang di antaranya berisi penentuan lebar sabuk hijau pada hutan mangrove, yaitu selebar 200 $\mathrm{m}$ di sepanjang pantai, sehingga tidak ada hak/lahan masyarakat yang masuk ke dalam kawasan Zona Sabuk hijau (Greenbelt) hutan lindung mangrove;

b. Untuk mengatasi kasus terjadinya Konversi Zona Sabuk Hijau (Greenbelt) menjadi tambak, maka perlu dibuat kontrak sosial antara pemerintah (DisHut dan DKP) dengan masyarakat pesisr Kota Singkawang melalui kesepakatan konservasi yang 
menyatakan bahwa masyarakat diijinkan untuk budidaya udang pada lahan tambak yang sudah ada, tetapi memiliki kewajiban-kewajiban sebagai berikut :

- Merehabilitasi tambak yang ada dengan penerapan pola tumpangsari antara mangrove dengan tambak (sylvofishery/wanamina). Cara/teknik silvofishery yang diterapkan adalah model empang parit tradisional dengan perbandingan luasan antara antara mangrove dan parit adalah 80\%: 20\%. diluar 200 m kawasan Zona Sabuk hijau (Greenbelt) hutan lindung mangrove .

- Masyarakat tidak boleh memperluas dan membuka lahan tambak baru di dalam kawasan Zona Sabuk Hijau (Greenbelt).

- Pihak pengelola memberikan ijin tambak ramah lingkungan dan masyarakat petambak harus membayar retribusi sebesar $1.5 \%$ dari hasil panen kepada pemerintah daerah untuk biaya pengamanan dan pelestarian mangrove.

- Masyarakat punya kewajiban untuk menjaga keutuhan dan kelestarian kawasan serta berperan dalam usaha pengamanan kawasan Zona Sabuk Hijau (Greenbelt) ekosistem mangrove.

- Masyarakat tidak boleh memperjual belikan lahan tambak di kawasan Zona Sabuk Hijau (Greenbelt) ekosistem mangrove.

- Masyarakat juga diberi kewajiban untuk melakukan usaha rehabilitasi pada lahan terbuka dengan menanam tanaman mangrove. Jenis mangrove yang ditanam hendak jenis yang cocok untuk daerah tersebut yaitu Avicennia alba dan Sonneratia alba

Pihak pengelola kawasan hendaknyanya melakukan monitoring dan evaluasi secara rutin untuk melihat apakah kesepakatan tersebut berjalan atau tidak. Jika terdapat pelangaran seperti pembukaan tambak baru oleh masyarakat, maka pihak berwajib (Dinas Kelautan\&Perikanan, Dinas Kehutanan dan Kepolisian) dapat melakukan tindakan penghancuran tambak tersebut dan masyarakat yang melakukannya dapat diproses secara hukum.

\section{SIMPULAN}

Dari hasil penelitian ini dapat disimpulkan sebagai berikut: Indeks Nilai Penting (INP) vegetasi mangrove di Pesisir Kota Singkawang untuk tingkat pohon tertinggi terdapat pada jenis Avicennia alba yaitu 265.95, lalu di ikuti oleh Sonneratia alba (25.10), Rhizophora mucronata (8.96), dan Excoecaria agallocha (0.00). INP yang besar pada jenis Avicennia alba dan Sonneratia alba menunjukan bahwa jenis ini merupakan jenis yang paling dominan dan mampu menyesuaikan diri dengan kondisi lingkungan yang ada; Nilai total manfaat ekonomi mangrove di Pesisir Kota Singkawang adalah sebesar Rp. 248.184.754.76/ha/thn atau sekitar 7 (tujuh) kali lebih besar jika bandingkan dengan nilai ekonomi tambak yang sebesar Rp. 35.425.000,00 /ha/thn. Hal ini menun-jukan bahwa lebih menguntungkan mangrove dibiarkan dalam kondisi lestari daripada dikonversi menjadi tambak. Begitu juga apabila nilai ekonomi tambak dibandingkan dengan nilai manfaat langsung ekosistem mangrove (Rp. 78.178.363.03/ha/thn), maka nilai ekonomi tambak tetap lebih kecil; Dilihat dari ketiga Faktor penyebab utama konversi ekosistem mangrove menjadi tambak diwilayah pesisir Kota Singkawang faktor yang paling dominan adalah Tingginya kebutuhan ekonomi yang dibarengi dengan kurangnya kesadaran akan kepentingan ekologis serta kepedulian masyarakat pesisir Kota Singkawang akan dampak lingkungan; Alternatif solusi untuk mengatasi pemasalahan dalam pengelolaan ekosistem mangrove di Pesisir Kota Singkawang adalah dengan memperbaiki dan memperkuat struktur kelembagaan agar lebih efektif sehingga menghasilkan performance yang lebih baik. Hal ini dilakukan dengan cara: (1) Batas (zonasi) Sabuk hijau (Greenbelt) sebagai areal yang dilindungi sesuai dengan Surat Keputusan Bersama Menteri Pertanian dan Menteri Kehutanan No. KB 550/264/Kpts/4/1984 dan No. 082/Kpts-II/1984 tanggal 30 April 1984 yang di antaranya menyebutkan bahwa lebar sabuk hijau hutan mangrove adalah $200 \mathrm{~m}$. Surat Keputusan Bersama ini selanjutnya dijabarkan oleh Departemen Kehutanan dengan mengeluarkan Surat Edaran No. 507/IV-BPHH/1990 yang di antaranya berisi penentuan lebar sabuk hijau pada hutan mangrove, yaitu selebar $200 \mathrm{~m}$ di sepanjang pantai, sehingga tidak ada hak/lahan masyarakat yang masuk ke dalam kawasan Zona Sabuk hijau (Greenbelt) hutan lindung mangrove; (2) memberikan akses terbatas kepada masyarakat untuk tetap dapat mengusahakan budidaya tambak udang sistem silvofishery (80\%: 20\%) dengan aturan dan kewajibankewajiban tertentu yang dituangkan dalam kesepakatan konservasi (kontrak sosial) diluar 200 m kawasan Zona Sabuk hijau (Greenbelt) hutan lindung mangrove.

\section{UCAPAN TERIMA KASIH}

Pada kesempatan yang baik ini, penulis ingin mengucapkan terima kasih sebesar-besarnya kepada:

1. Prof. Dr. Ir. H. Otong Suhara Djunaedi, MS., selaku Ketua Komisi Pembimbing.

2. Dr. Ir. Zahidah Hasan., MS., selaku Anggota Komisi Pembimbing.

3. Dr. Ir. Iskandar, Msi., selaku Ketua Sidang.

4. Prof. Dr. Ir. H. Dulmi'ad Iriana selaku Penelaah.

5. Prof. Dr. Ir. H. Masyamsir, MS., selaku Penelaah.

6. Prof. H. Yayat Dhahiyat, Ph.D., selaku Penelaah

7. Dr. Ir. Ayi Yustiati M.Sc., selaku Dekan Fakultas 
Perikanan dan Ilmu Kelautan Universitas Padjadjaran.

8. Kepala Laboratorium dan semua staf pengajar Program Studi Perikanan atas segala ilmu dan pengarahan yang telah diberikan selama penulis menimba ilmu di Program Pascasarjana Universitas Padjadjaran.

9. Prof. Dr. Ir. Mahfud Arifin, MS., selaku Direktur Program Pascasarjana Universitas Padjadjaran beserta staf.

10. Prof. Dr. Ir. Ganjar Kurnia, DEA., selaku Rektor Universitas Padjadjaran.

Karya ilmiah ini kupersembahkan untuk Istriku "Febrina Arli" dan kedua putraku "Pangeran Rafi Indi E Ardi dan Almi'raj Gumilang Indi E Ardi” yang tersayang dan tercinta, terima kasih atas pengertian, pengorbanan dan dukungannya yang tulus selama menunggu selesainya masa studiku.

Tidak lupa pula juga untuk Ibunda "D. Tien Ratniti", Ayahanda "H. Aqil Syail", Bapak Mertua "Arbain (Alm)", Ibu Mertua "Nurlaeli" dan seluruh saudarasaudaraku yang juga sangat kusayangi. Serta teman- teman seperjuangan angkatan 2010 (Amenica Machado Fernandes, Martesia Klarissa dan Wishal Miggy Dasanova) Program Studi Manajemen Sumberdaya dan Lingkungan Perairan, Program Pascasarjana (S-2) Universitas Padjadjaran Bandung yang saya cintai dan saya banggakan.

\section{DAFTAR PUSTAKA}

Adrianto L. 2006. Pengenalan konsep dan metodologi valuasi ekonomi sumberdaya pesisir dan laut. Sinopsis. PKSPL. IPB. Bogor.

Bengen DG. 2004. Ekosistem dan sumberdaya alam pesisir dan laut serta prinsip pengelolaannya. Sinopsis. PKSPL. IPB. Bogor.

English S., Wilkinson C. and Baker V. (editors). 1994. Survey manual for tropical marine resources. Australian Institute of Marine Science. Townsville

Ruitenbeek HJ. 1991. Mangrove management: An economic analysis of management option with a focus on Bintuni Bray. EMDI. Irian Jaya. 